\title{
Successful Rescue Therapy with Pumpless Extracorporeal Carbon Dioxide Removal in a Patient with Persistent Air Leakage Due to Empyema
}

\author{
Jaeyoung Cho, Yeon Joo Lee, Jae-Ho Lee, Choon-Taek Lee, and Young-Jae Cho \\ Division of Pulmonary and Critical Care Medicine, Department of Internal Medicine, Seoul National University Bundang Hospital, \\ Seoul National University College of Medicine, Seongnam, Korea
}

\begin{abstract}
A young metastatic lung cancer patient developed empyema due to an infection with carbapenem-resistant Acinetobacter baumannii. Hydropneumothorax was detected and managed by a tube thoracotomy. However, persistent air leakage through the chest tube was observed due to the presence of a bronchopleural fistula (BPF). As hypercapnic respiratory failure had progressed and the large air leak did not diminish by conservative management, a pumpless extracorporeal lung assist ( $p E C L A)$ device was inserted. The $p E C L A$ allowed the patient to be weaned from mechanical ventilation and the BPF to heal. The present case shows the effective application of $\mathrm{pECLA}$ in a patient with empyema complicated with BPF and severe hypercapnic respiratory failure. pECLA enabled us to minimize airway pressure to aid in the closure of the BPF in the mechanically ventilated patient.
\end{abstract}

Key Words: bronchial fistula; empyema; hydropneumothorax; hypercapnia; pumpless extracorporeal lung assist; respiratory insufficiency.

A bronchopleural fistula (BPF) is a severe complication of a variety of lung diseases or injuries. The most common cause of BPF is the postoperative pulmonary complication after lung resection, followed by necrotizing lung disease [1]. BPF is associated with an increased morbidity and mortality. Overall mortality has been reported as $67 \%$ in patients with BPF receiving mechanical ventilation [2]. Treatment options of BPF range from medical therapy including the use of bronchoscopy and different sealing compounds to surgical procedures. However, the optimal therapy is controversial and the management of BPF is challenging.

A pumpless extracorporeal lung assist (pECLA) device or interventional lung assist system (iLA; Novalung, Talheim, Germany) has been used in patients with acute respiratory distress syndrome (ARDS) $[3,4]$. There were also several cases where pECLA had been effectively used as a rescue therapy for patients with intractable asthma [5], interstitial lung disease [6], and bridge to lung transplantation [7]. However, there were only a few cases where pECLA was applied in patients with both persistent air leaks and respiratory failure [8-10]. Here we describe our experience with pECLA in a patient with empyema complicated with BPF and severe hypercapnic respiratory failure. pECLA enable us to minimize airway pressures to favor the closure of BPF in the mechanically ventilated patient.

\footnotetext{
Received on March 14, 2016 Revised on July 31, 2016 Accepted on August 7, 2016

Correspondence to: Young-Jae Cho, Division of Pulmonary and Critical Care Medicine, Department of Internal Medicine, Seoul National University Bundang Hospital, Seoul National University College of Medicine, 82 Gumi-ro 173beon-gil, Bundang-gu, Seongnam 13620, Korea

Tel: +82-31-787-7058, Fax: +82-31-787-4052, E-mail: lungdrcho@gmail.com

*No potential conflict of interest relevant to this article was reported.
}

cc This is an Open Access article distributed under the terms of the Creative Commons Attribution Non-Commercial License (http://creativecommons.org/ licenses/by-nc/4.0/) which permits unrestricted non-commercial use, distribution, and reproduction in any medium, provided the original work is properly cited. Copyright (c) 2017 The Korean Society of Critical Care Medicine 


\section{Case Report}

A 44-year-old male patient (height, $159 \mathrm{~cm}$; body weight, $58 \mathrm{~kg}$; body mass index, $23 \mathrm{~kg} / \mathrm{m}^{2}$ ) presented to the emergency department of a teaching hospital with a 3-day history of purulent sputum and dyspnea. He was former smoker (10 pack-years) who had been diagnosed with stage IV non-small cell lung cancer with metastasis to the brain, bones, left adrenal gland (Figure 1). The histologic subtype was poorly differentiated adenosquamous carcinoma with a deletion in exon 19 of the epidermal

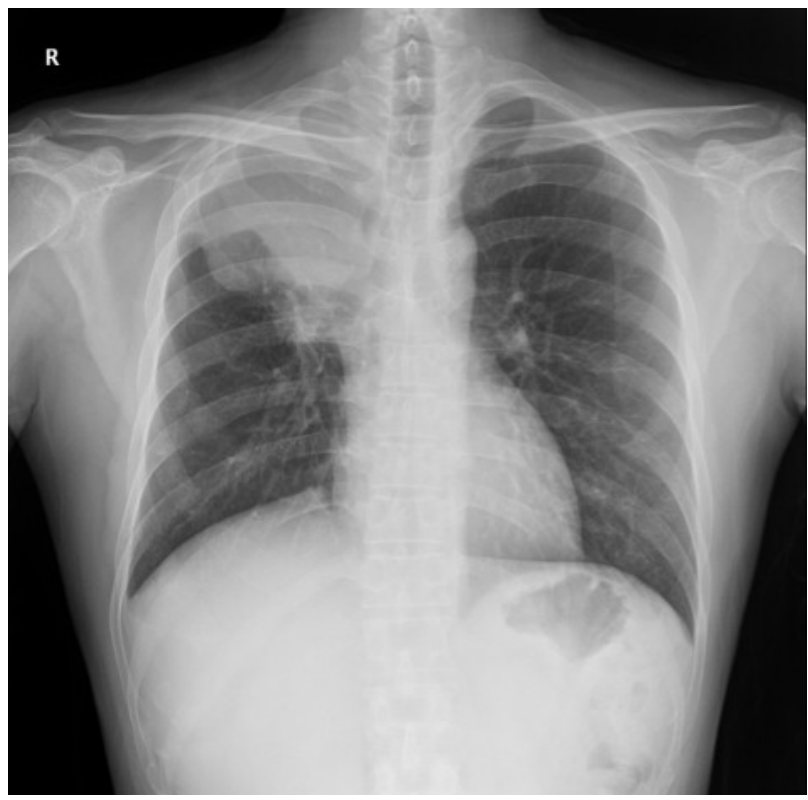

Figure 1. Initial chest radiography from the diagnosis of lung cancer. growth factor receptor gene. He received gefitinib at 250 mg orally once daily over the previous 2 months. At the emergency department, he was tachycardic (a heart rate of 141 beats/min), tachypnoeic (a respiratory rate of 44 breaths/min), and hypoxemic (a pulse oximetry saturation of $87 \%$ despite of oxygen supplementation through a full facial mask) although he was not hypotensive (blood pressure of 146/94 mmHg). Blood gases showed hypoxemia (pH, 7.379; $\mathrm{PaCO}_{2}, 46.2 \mathrm{mmHg} ; \mathrm{PaO}_{2}, 64.6$ mmHg; $\left.\mathrm{HCO}_{3}{ }^{-}, 26.7 \mathrm{mmol} / \mathrm{L}\right)$. He was admitted to our intensive care unit (ICU) with a Sequential Organ Failure Score of 10, and an Acute Physiology and Chronic Health Evaluation II of 23. Elevated levels of inflammatory markers were detected: white blood cells $68.7 \times 10^{9}$ cells/L (reference range, 4.0 to $10.0 \times 10^{9}$ cells $/ \mathrm{L}$ ), C-reactive protein $>30.0 \mathrm{mg} / \mathrm{dl}$ (reference range, 0 to $0.5 \mathrm{mg} / \mathrm{dl}$ ), and procalcitonin $11.0 \mathrm{ng} / \mathrm{ml}$ (reference range, 0 to $0.5 \mathrm{ng} / \mathrm{ml}$ ). Chest X-rays revealed right hydropneumothorax and bilateral dense consolidation (Figure 2A), even though chest computed tomography (CT) showed that his primary lung cancer had decreased in size from 7.5 to $4.9 \mathrm{~cm}$. As peripheral BPF was suspected based on the CT (Figure $2 \mathrm{~B}$ and $\mathrm{C}$ ), a chest tube was inserted into the right thorax. Pus was drained and pleural fluid analysis revealed a pH of 7.148, glucose of $2 \mathrm{mg} / \mathrm{dl}$, lactate dehydrogenase $(\mathrm{LDH})$ of greater than $6,000 \mathrm{U} / \mathrm{L}$, and total protein of $2.3 \mathrm{~g} / \mathrm{dl}$. As the pleural fluid was thick and viscous, pleural LDH and protein were measured using the diluted
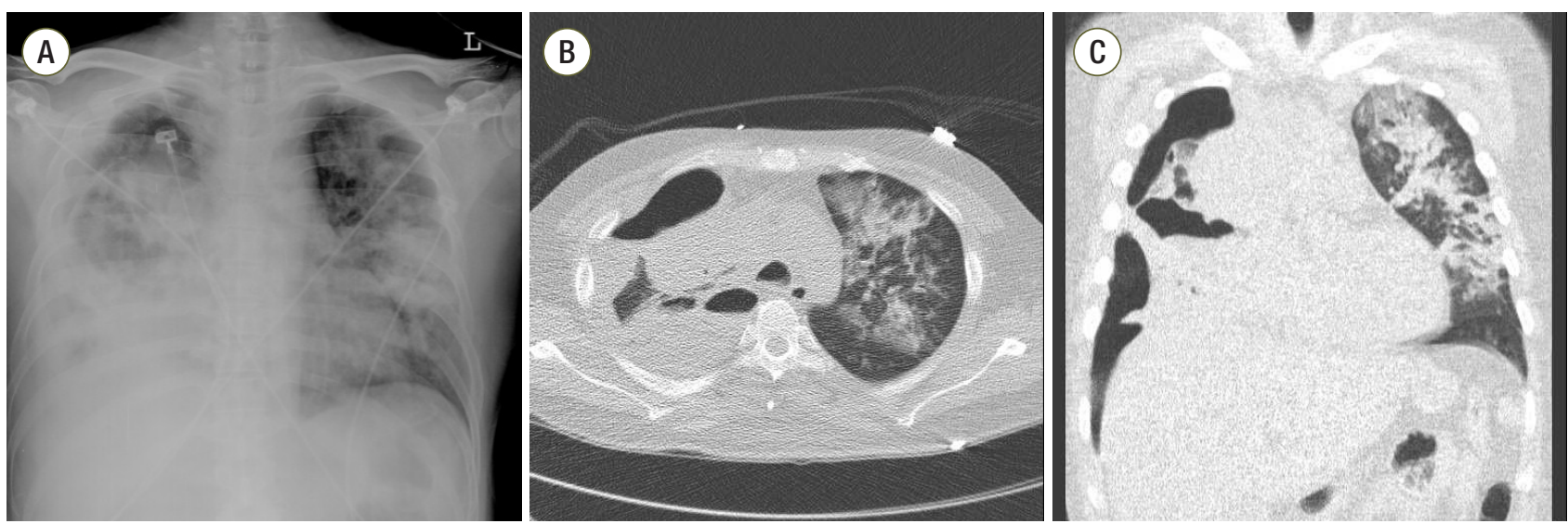

Figure 2. Chest radiography $(A)$ and chest computed tomography images $(B, C)$ from the day of admission to the intensive care unit. 
sample. A white blood cell count of the fluid was 24.4 $\times 10^{9}$ cells $/ \mathrm{L}$, however, the differential count could not be performed because of severe degenerative change of the cells in the fluid. Right empyema and left pneumonia were diagnosed and empirical intravenous antibiotics of piperacillin/tazobactam (4.5 g q6h) and vancomycin (1 g q12h) were started immediately. During the night of ICU admission, respiratory failure progressed, so the patient was intubated and mechanical ventilation started using pressure-controlled ventilation (PCV) with inspiratory pressures of $25 \mathrm{cmH}_{2} \mathrm{O}$, positive end-expiratory pressure (PEEP) of $5 \mathrm{cmH}_{2} \mathrm{O}$, respiratory rate of 25 breaths $/ \mathrm{min}$, and $\mathrm{FiO}_{2}$ of 0.9 .

On ICU day 4, blood gases showed marked hypercapnia and respiratory acidosis $\left(\mathrm{pH}, 7.264 ; \mathrm{PaCO}_{2}, 79.4\right.$ $\mathrm{mmHg} ; \mathrm{PaO}_{2}, 157.2 \mathrm{mmHg} ; \mathrm{HCO}_{3}^{-}, 35.2 \mathrm{mmol} / \mathrm{L}$ ) while on PCV with inspiratory pressures of $30 \mathrm{cmH}_{2} \mathrm{O}$, PEEP of $3 \mathrm{cmH}_{2} \mathrm{O}$, respiratory rate of 40 breaths $/ \mathrm{min}$, and $\mathrm{FiO}_{2}$ of 0.6 . When the ventilator modality was changed to volume-controlled ventilation with a tidal volume of $250 \mathrm{ml}$ (approximately $4.5 \mathrm{ml} / \mathrm{kg}$ predicted body weight [PBW]) and respiratory rate of 40 breaths $/ \mathrm{min}$, it generated unacceptably high peak inspiratory pressure $\left(40 \mathrm{cmH}_{2} \mathrm{O}\right)$, and hypercapnia $\left(\mathrm{PaCO}_{2} 70.9 \mathrm{mmHg}\right)$ in conjunction with respiratory acidosis (pH 7.307) did not markedly improve. Due to persistent air leakage through the chest tube, a low PEEP was maintained at 3 to $4 \mathrm{cmH}_{2} \mathrm{O}$ and another chest tube was inserted in the right side (Figure 3A). However, oxygenation impairment was relatively moderate $\left(\mathrm{PaO}_{2} / \mathrm{FiO}_{2} 151 \mathrm{mmHg}\right)$. A norepinephrine infusion, which was started on ICU day 2 at $4 \mu \mathrm{g} / \mathrm{min}$, subsequently increased to $16 \mu \mathrm{g} / \mathrm{min}$ for hypotension. At midday of ICU day 4, we decided to use pECLA. pECLA was connected to the left femoral artery (15 Fr) and the right femoral vein $(17 \mathrm{Fr})$ using the Seldinger technique (Figure 3B). A continuous infusion of heparin $(1,000 \mathrm{IU} / \mathrm{h})$ was initiated to maintain activated partial thromboplastin time in the range of 68 to 90 seconds. Within 30 minutes $\mathrm{PaCO}_{2}$ decreased to $49.6 \mathrm{mmHg}$ and arterial $\mathrm{pH}$ normalized, even though minute ventilation was lowered from 9.58 to $4.32 \mathrm{~L} / \mathrm{min}$ at a sweep gas flow of $3 \mathrm{~L} / \mathrm{min}$ (Table 1, Figure 4). The norepinephrine infusion was tapered off over 40 hours of pECLA as acidosis was corrected. Lung protective ventilation $(220 \mathrm{~mL}$ tidal volume, $3.9 \mathrm{ml} / \mathrm{kg}$ PBW) was enabled using PCV, with inspiratory pressures of $28 \mathrm{cmH}_{2} \mathrm{O}$ and PEEP of $4 \mathrm{cmH}_{2} \mathrm{O}$.

Flexible bronchoscopy was performed on ICU day 5 . BPF was not identified by bronchoscopy, and bronchoal-
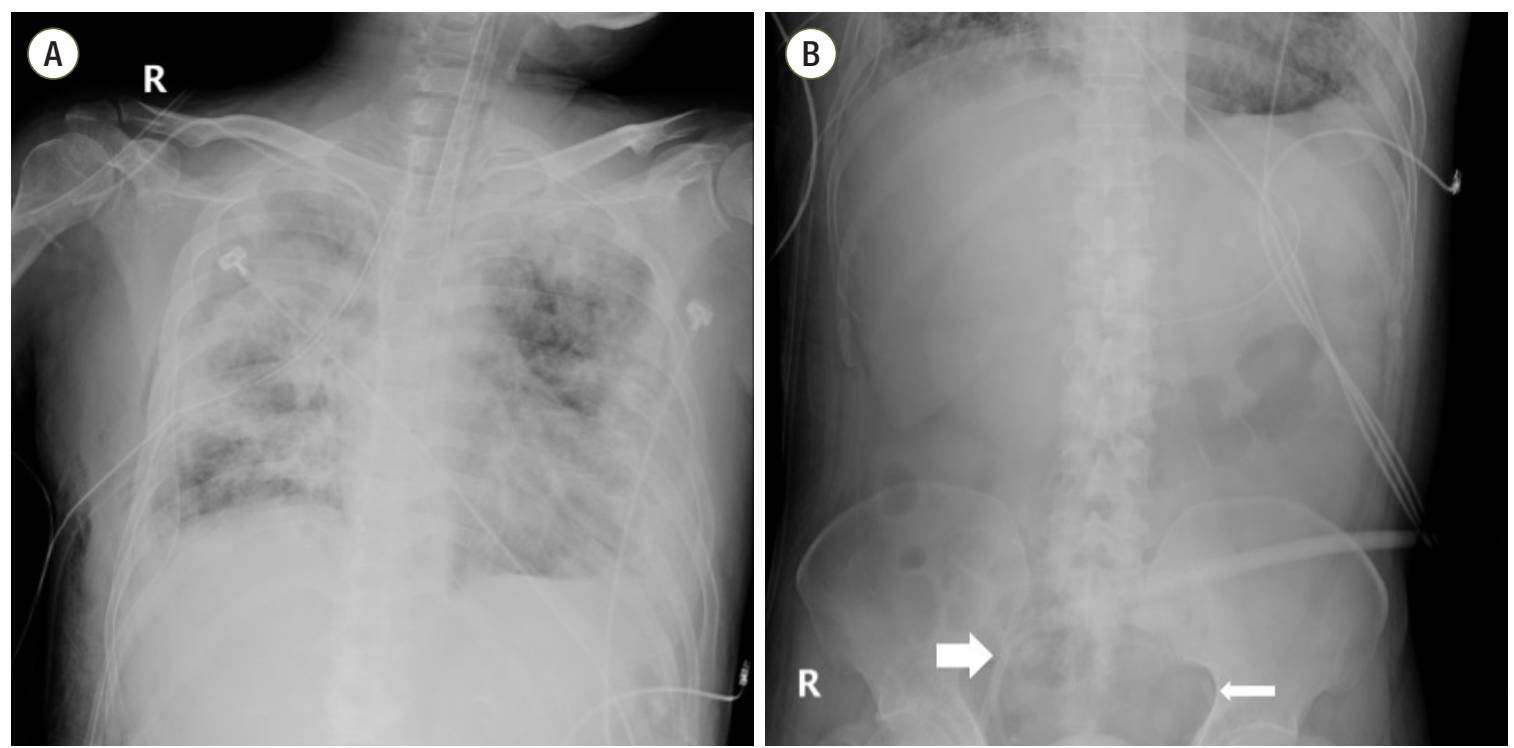

Figure 3. Chest radiography $(A)$ and abdominal simple radiography $(B)$ from the day of pumpless extracorporeal lung assist ( $p E C L A)$ insertion (ICU day 4). The pECLA was connected to the left femoral artery (thin arrow) and the right femoral vein (thick arrow). ICU: intensive care unit. 


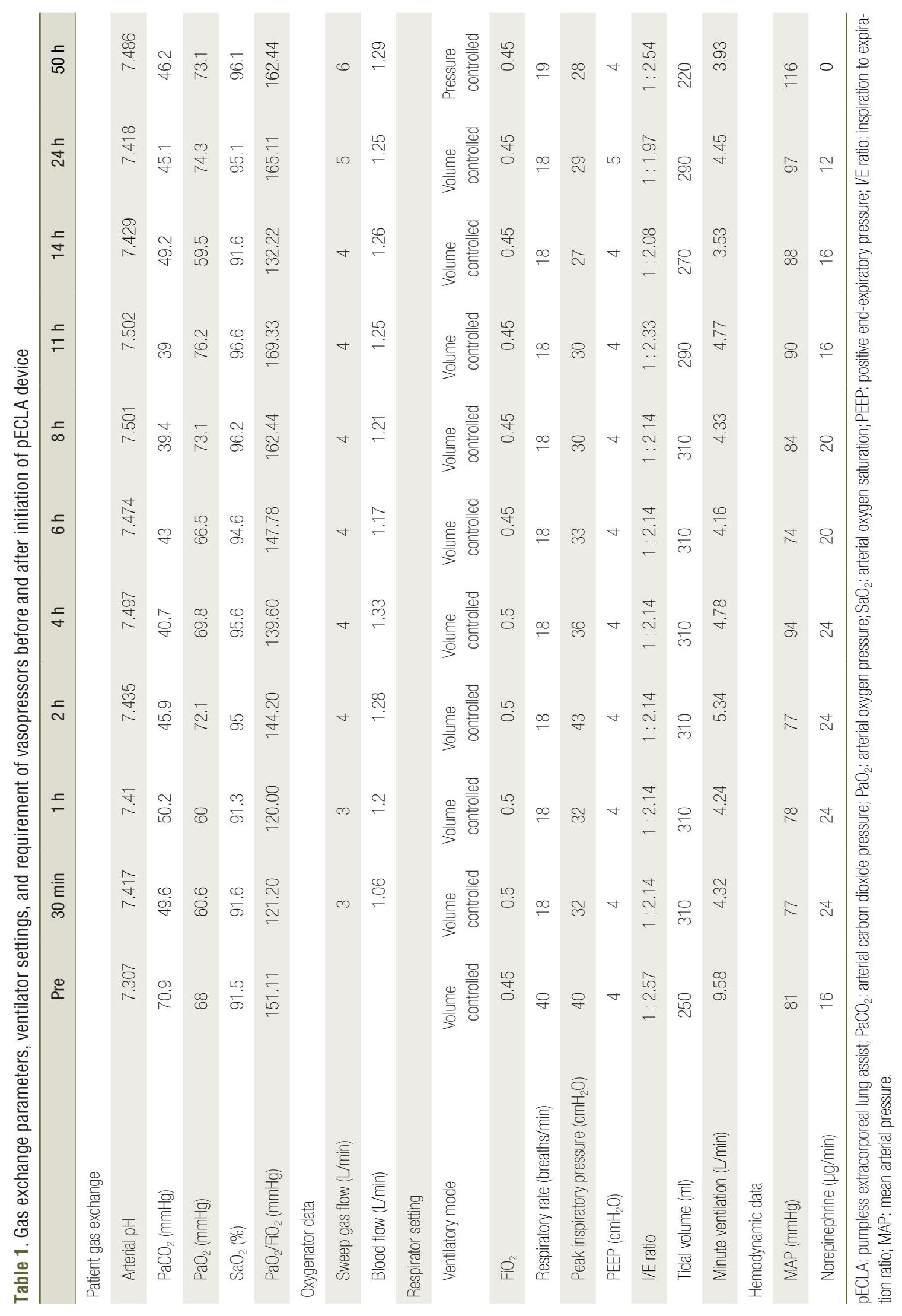


veolar lavage (BAL) was done. As BAL and pleural fluids revealed carbapenem-resistant Acinetobacter baumannii on ICU day 8 , intravenous colistin was initiated (Figure 5). Infection was gradually controlled by insert- ing two additional chest tubes for drainage of remained empyema, and by repeated bronchoscopic toileting. The patient was weaned from pECLA in 10 days, and there were no complications related to the extracorporeal
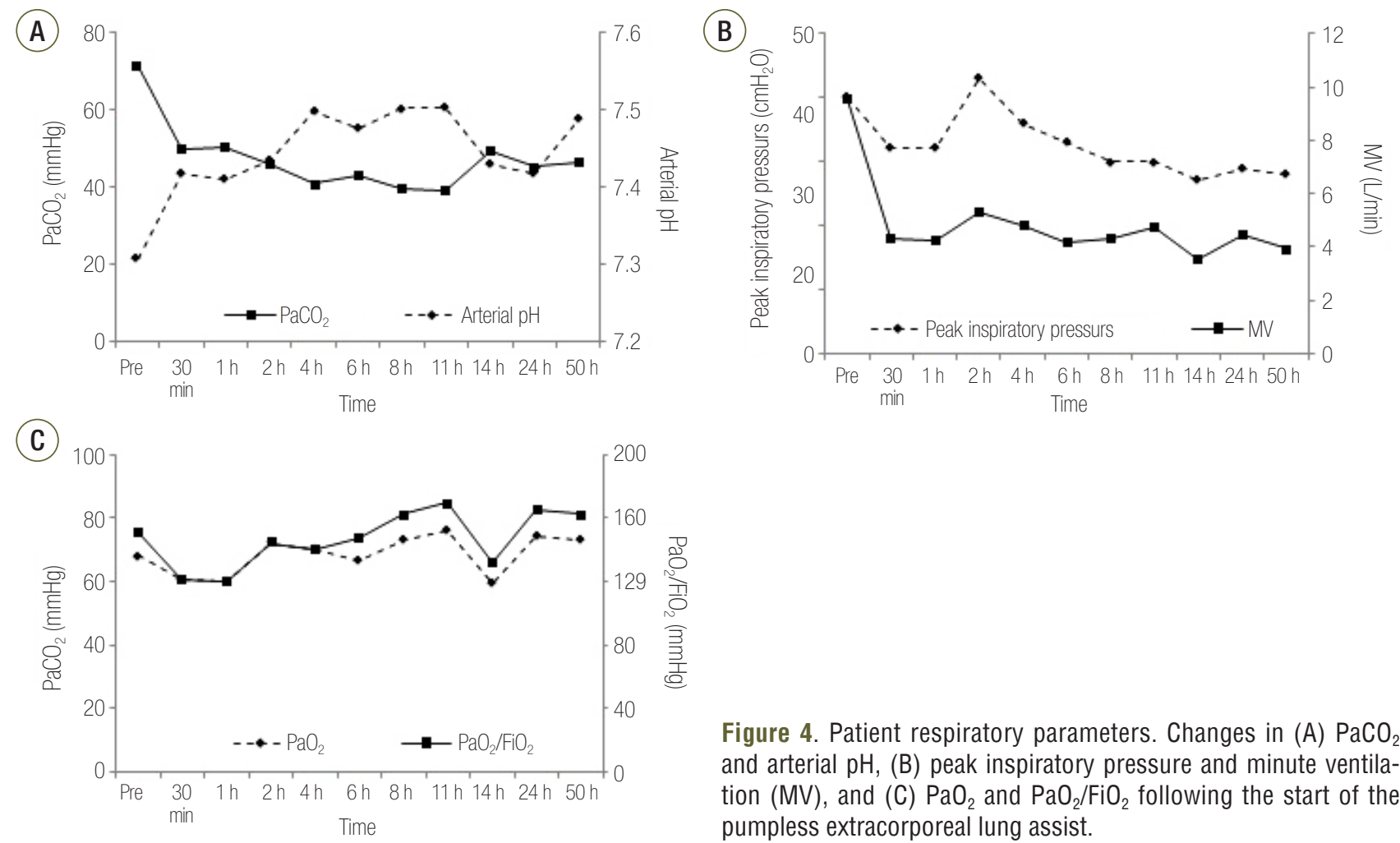

Figure 4. Patient respiratory parameters. Changes in (A) $\mathrm{PaCO}_{2}$ and arterial $\mathrm{pH}$, (B) peak inspiratory pressure and minute ventilation (MV), and (C) $\mathrm{PaO}_{2}$ and $\mathrm{PaO}_{2} / \mathrm{FiO}_{2}$ following the start of the pumpless extracorporeal lung assist.

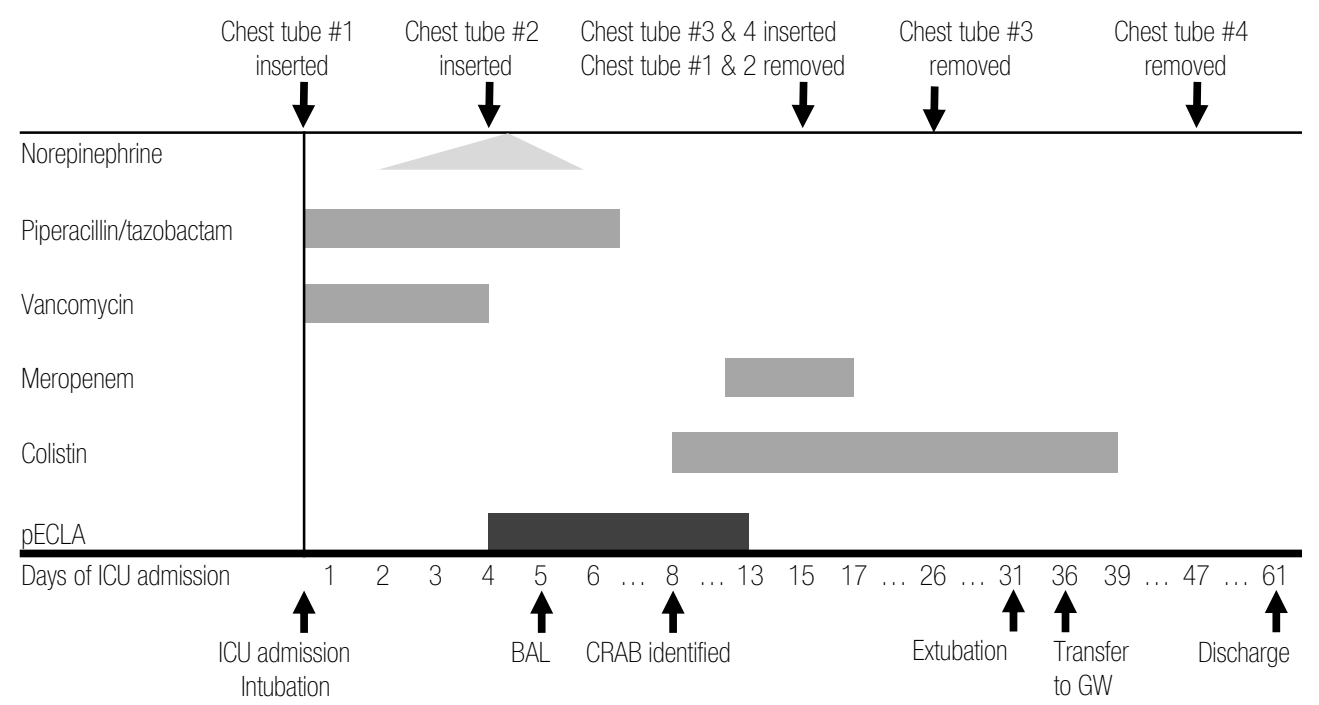

Figure 5. Timetable of the use of antibiotics and important events in the patient's hospital course. pECLA: pumpless extracorporeal lung assist; ICU: intensive care unit; BAL: bronchoalveolar lavage; CRAB: carbapenem-resistant Acinetobacter baumannii; GW: general ward. 
therapy. Gefitinib was restarted on ICU day 27, since the primary lung cancer had slightly increased in size on the serial CT follow-up. The patient was weaned from invasive mechanical ventilation on ICU day 31 , and transferred to a general ward after 36 days of admission. Intermittent air leaks were completely resolved after 40 days of admission and the last chest tube was removed a week later. After rehabilitation in the ward, the patient was discharged after 2 months of hospitalization.

\section{Discussion}

We described the case of a patient with empyema complicated with BPF and severe hypercapnic respiratory failure. The use of pECLA for extracorporeal carbon dioxide removal enabled the patient to reach normocapnia and correct acidosis. By reducing the plateau pressure, it might be beneficial to create proper conditions for reducing air leaks and closing BPF.

Previous cases of the use of pECLA in refractory air leaks were mainly reported from European countries. Pesenti et al. [8] reported their experience with a patient with emphysema and bilateral pneumothorax in whom pECLA allowed them to resolve recurrent pneumothorax. Recently the same authors reported a patient with posttraumatic ARDS with bilateral air leaks. In the case, they successfully used pECLA and achieved a closure of the BPF after the failure of other conservative measures [10]. Hommel et al. [9] described four patients with bronchial fistulae who had undergone surgical repair and developed ARDS. The authors said that the use of pECLA enabled lower airway pressures, which may have contributed to protect bronchial reconstruction.

Treatment options of BPF include medical therapy and surgical procedures. However, the success rates have been variable and the treatment plan should be individualized. In cases of empyema, drainage of fluid collection and administration of adequate antibiotics are required. Suction on chest tubes should be minimized to decrease the gradient between airway pressures and the pleural space because the use of negative pressure can increase the flow though the fistula and prevent fistula closure [1]. When mechanical ventilation is required in patients with persistent air leaks, the flow though the fistula tract interferes with healing of fistula itself and causes loss of tidal volume. To limit flow though the BPF, low PEEP can be applied as we did. The surgical treatment of BPF can be considered. However, empyema by carbapenem-resistant Acinetobacter baumannii, which was not fully controlled, precluded the surgical approach in our case. Another option of bronchoscopic intervention with different glues or coils was not applicable because the fistula tract was not visualized by bronchoscopy.

In this circumstance, we placed pECLA as a rescue therapy for the persistent air leak. As a result, the patient was successfully weaned from mechanical ventilation and the refractory air leak was eventually resolved. The use of pECLA in the present case would be beneficial for the following two reasons: (1) low plateau pressure minimizes flow through BPF, thus promotes healing and closure of the tract; (2) extracorporeal carbon dioxide removal leads to improvement in respiratory acidosis.

Our report describes the successful use of pECLA in a patient with a persistent air leak secondary to empyema and hypercapnic respiratory failure. As pECLA allows weaning from mechanical ventilation and resolution of air leaks, it can be used as a rescue therapy in patients with persistent air leaks.

\section{ORCID}

Young-Jae Cho http://orcid.org/0000-0001-6943-4462

\section{References}

1. Lois M, Noppen M. Bronchopleural fistulas: an overview of the problem with special focus on endoscopic management. Chest 2005;128:3955-65.

2. Pierson DJ, Horton CA, Bates PW. Persistent bron- 
chopleural air leak during mechanical ventilation: a review of 39 cases. Chest 1986;90:321-3.

3. Bein T, Weber F, Philipp A, Prasser C, Pfeifer M, Schmid FX, et al. A new pumpless extracorporeal interventional lung assist in critical hypoxemia/hypercapnia. Crit Care Med 2006;34:1372-7.

4. Flörchinger B, Philipp A, Klose A, Hilker M, Kobuch R, Rupprecht L, et al. Pumpless extracorporeal lung assist: a 10-year institutional experience. Ann Thorac Surg 2008;86:410-7.

5. Jung C, Lauten A, Pfeifer R, Bahrmann P, Figulla HR, Ferrari M. Pumpless extracorporeal lung assist for the treatment of severe, refractory status asthmaticus. J Asthma 2011;48:111-3.

6. Petzoldt M, Braune S, Bittmann I, Kluge S. Rescue therapy with a pumpless extracorporeal lung assist device in a patient with acute interstitial lung disease and severe refractory hypercapnia. Respir Care 2012;57:293-7.
7. Fischer S, Hoeper MM, Bein T, Simon AR, Gottlieb $\mathrm{J}$, Wisser $\mathrm{W}$, et al. Interventional lung assist: a new concept of protective ventilation in bridge to lung transplantation. ASAIO J 2008;54:3-10.

8. Pesenti A, Rossi GP, Pelosi P, Brazzi L, Gattinoni L. Percutaneous extracorporeal $\mathrm{CO} 2$ removal in a patient with bullous emphysema with recurrent bilateral pneumothoraces and respiratory failure. Anesthesiology 1990;72:571-3.

9. Hommel M, Deja M, von Dossow V, Diemel K, Heidenhain C, Spies C, et al. Bronchial fistulae in ARDS patients: management with an extracorporeal lung assist device. Eur Respir J 2008;32:1652-5.

10. Bombino M, Patroniti N, Foti G, Isgrò S, Grasselli G, Pesenti A. Bronchopleural fistulae and pulmonary ossification in posttraumatic acute respiratory distress syndrome: successful treatment with extracorporeal support. ASAIO J 2011;57:336-40. 